\title{
Antalya İli Gazipaşa ve Alanya İlçelerinde Domates Yetiştirilen Sera Topraklarının Verimlilik Özellikleri ve Bitkilerin Beslenme Durumlarının Belirlenmesi
}

\author{
Filiz Öktüren Asri* Nuri Arı \\ Batı Akdeniz Tarımsal Araştırma Enstitüsü Müdürlüğü, Antalya \\ *Sorumlu yazar: filiz.okturenasri@tarimorman.gov.tr
}

\author{
Cevdet F. Özkan
}

Dilek Güven

\section{$\ddot{\mathbf{O} z}$}

$\mathrm{Bu}$ çalışma, Gazipaşa ve Alanya ilçelerinde tek ürün domates yetiştirilen sera topraklarının verimlilik özelliklerinin ve bitkilerin beslenme durumlarının belirlenmesi amacıyla yapılmıştır. Bu amaçla Gazipaşa ilçesinde 17, Alanya ilçesinde ise 9 farklı seradan toprak ve yaprak örnekleri alınmıştır. Alınan toprak örneklerinde bünye, $\mathrm{pH}$, elektriksel iletkenlik (EC), kireç $\left(\mathrm{CaCO}_{3}\right)$, organik madde, toplam azot $(\mathrm{N})$, alınabilir fosfor (P), alınabilir potasyum (K), kalsiyum (Ca), magnezyum $(\mathrm{Mg})$, alınabilir demir (Fe), çinko (Zn), mangan $(\mathrm{Mn})$ ve bakır $(\mathrm{Cu})$; yaprak örneklerinde ise toplam $\mathrm{N}, \mathrm{P}, \mathrm{K}, \mathrm{Ca}, \mathrm{Mg}, \mathrm{Fe}, \mathrm{Zn}, \mathrm{Mn}$ ve $\mathrm{Cu}$ analizleri yapılmıştır. Toprak analizi sonuçlarına göre; her iki ilçenin toprakları da hafif alkalin ve alkalin karakterde, düşük kireç ve organik madde miktarına sahiptir. Toprak örneklerinin toplam $\mathrm{N}$, alınabilir $\mathrm{Fe}, \mathrm{Zn}, \mathrm{Mn}$ ve $\mathrm{Cu}$ konsantrasyonları iyi, alınabilir $\mathrm{Mg}$ ve Ca konsantrasyonları ise yüksektir. Alınabilir potasyum konsantrasyonları düşükten çok yüksek sınıfına değişkenlik göstermiştir. Domates yaprak örneklerinin toplam N, P, Ca ve Mg konsantrasyonları yeterli ve yüksek; toplam $\mathrm{Fe}, \mathrm{Zn}, \mathrm{Mn}$ ve $\mathrm{Cu}$ konsantrasyonları yeterli ve $\mathrm{K}$ konsantrasyonları ise düşüktür.

Anahtar Kelimeler: Besin elementleri, Domates, Toprak verimliliği, Beslenme durumu.

\section{Determination of Fertility Properties of Tomato Grown Greenhouse Soils and Plant Nutrition Status in the Gazipaşa and Alanya Districts}

\section{Abstract}

This study was carried out to determine some fertility properties of greenhouse soils and plant nutrition status of tomato plants in the Gazipasa and Alanya. For this aim, soil and leaf samples from 17 greenhouses in Gazipasa district and 9 greenhouses in Alanya district were taken. The analyses were made to determine $\mathrm{pH}$, electrical conductivity $(\mathrm{EC})$, lime $\left(\mathrm{CaCO}_{3}\right)$, texture, organic matter, total nitrogen $(\mathrm{N})$, available phosphorus $(\mathrm{P})$, available potassium $(\mathrm{K})$, calcium $(\mathrm{Ca})$, magnesium $(\mathrm{Mg})$, available iron $(\mathrm{Fe})$, zinc $(\mathrm{Zn})$, manganese $(\mathrm{Mn})$ and copper $(\mathrm{Cu})$ in soil samples and total $\mathrm{N}, \mathrm{P}, \mathrm{K}, \mathrm{Ca}, \mathrm{Mg}, \mathrm{Fe}, \mathrm{Zn}, \mathrm{Mn}$ and $\mathrm{Cu}$ in leaf samples. According to soil analysis results, soil samples were slightly alkaline and alkaline, poor organic matter content and low calcareous in both districts. The concentrations of total $\mathrm{N}$, available $\mathrm{Fe}, \mathrm{Zn}, \mathrm{Mn}$ and $\mathrm{Cu}$ in soil samples were generally sufficient while the concentrations of available $\mathrm{Mg}$ and $\mathrm{Ca}$ were high in each district. Available $\mathrm{K}$ concentration levels ranged from very poor to very high. The results of leaf analysis showed that the classifications of nutrient elements in each district were as follows the concentrations of total N, P, Ca and $\mathrm{Mg}$ were sufficient and high, the concentrations of total $\mathrm{Fe}, \mathrm{Zn}, \mathrm{Mn}$, and $\mathrm{Cu}$ were sufficient, and total $\mathrm{K}$ concentration were low.

Keywords: Nutrient elements, Tomato, Soil fertility, Nutritional status.

\section{Giriş}

Dünya'da en fazla tüketilen sebze türü domatestir. Ülkemiz domates üretim miktarı açısından (12.61 milyon ton) Çin, Hindistan ve ABD’nin ardından dünyada 4. sırada yer almaktadır (FAO, 2017). Türkiye toplam sebze üretiminin \%42'sini domates oluşturmaktadır. Üretilen domatesin \%71,3'ü sofralık, \%29,7'si endüstriyel üretimde (salça, ketçap vs.) kullanılmaktadır (Tatar ve Pirinç, 2017). Örtüaltı domates üretiminin \%77.6'sı Akdeniz Bölgesi'nden karşılanmaktadır. Söz konusu üretimin \%62,5'i Antalya ilinde gerçekleştirilmektedir (Kandemir ve ark., 2016). Üretilen domatesin önemli bir kısmı Rusya, Irak ve Romanya gibi ülkelere ihraç edilirken, bir kısmı da iç pazarda değerlendirilmektedir (Aksoy ve Kaymak, 2016). İhracatçı ülkeler taze domatese ilişkin kalite standartlarının uygulanmasında uniform büyüklüğe, tada ve aromaya, antioksidan içeriğine, olgunluğa 
ve görselliğe önem vermektedir. Standartta dikkate alınan bu özellikler tür ve çeşidin genetik özelliklerine ve bitkinin beslenme durumuna bağlıdır (Akınoğlu ve Korkmaz, 2016). Meyve şekli ve boyutu düzgün, içi boş olmayan, yüksek titre edilebilir asitlik ve/veya şeker oranına sahip, kaliteli domates meyvesi elde edilmesi için bitkinin tüm besin elementlerince dengeli beslenmesi gerekmektedir. Beslemenin domates meyve kalitesi üzerine etkileri bilindiğinden, uzun yetiştiricilik dönemi süresince yoğun bir gübre kullanımı söz konusudur. Uygulamadaki durumun bilinmesi araştırıcıları yetiştiricilik yapılan sera topraklarının verimlilik durumlarını belirlemeye yöneltmiştir. Arı ve ark. (2019), Antalya ili Demre ilçesinde domates yetiştirilen sera topraklarının alınabilir fosfor $(\mathrm{P})$, potasyum $(\mathrm{K})$, kalsiyum $(\mathrm{Ca})$ ve magnezyum $(\mathrm{Mg})$ konsantrasyonlarının yeterli olduğunu ancak yaprak örneklerinin \%40'ının azot $(\mathrm{N}), \% 44$ 'ünün ise $\mathrm{K}$ konsantrasyonunun noksan sınıfinda yer aldığını bildirmişlerdir. Özkan (2008), Antalya ve çevresi örtüaltı tek ürün domates yetiştirilen sera topraklarının tuz ve kireç miktarları ile toplam N, alınabilir P ve K konsantrasyonlarının yüksek olduğunu tespit etmiş̧tir. Maltaş ve Kaplan (2015), Antalya Merkez ilçede örtüaltı güzlük domates yetiştirilen sera topraklarının makro ve mikro besin elementi konsantrasyonlarının yeterli olduğunu ancak alınan yaprak örneklerinin tamamının $\mathrm{K}$ konsantrasyonunun yetersiz düzeyde olduğunu belirtmişlerdir.

Antalya Merkez ve ilçelerinde yaygın olarak yetiştiriciliği yapılan ve önemli bir gelir kaynağ 1 olan domates bitkisinin beslenme sorunlarını araştırmak ve çözüm önerileri geliştirmek amacıyla yapılan bu çalışmada, Antalya ili Gazipaşa ve Alanya ilçelerindeki sera topraklarının verimlilik düzeyleri ve bitkilerin beslenme durumları araştırılmıştır.

\section{Materyal ve Yöntem}

2013-2014 domates yetiştiricilik döneminde Gazipaşa ilçesindeki 17 ve Alanya ilçesindeki 9 farklı seradan toprak ve yaprak örnekleri alınmıştır. Örneklerin alındığı yerler Şekil 1 ve 2'de, koordinatlar ise Çizelge 1 ve 2 'de gösterilmiştir.

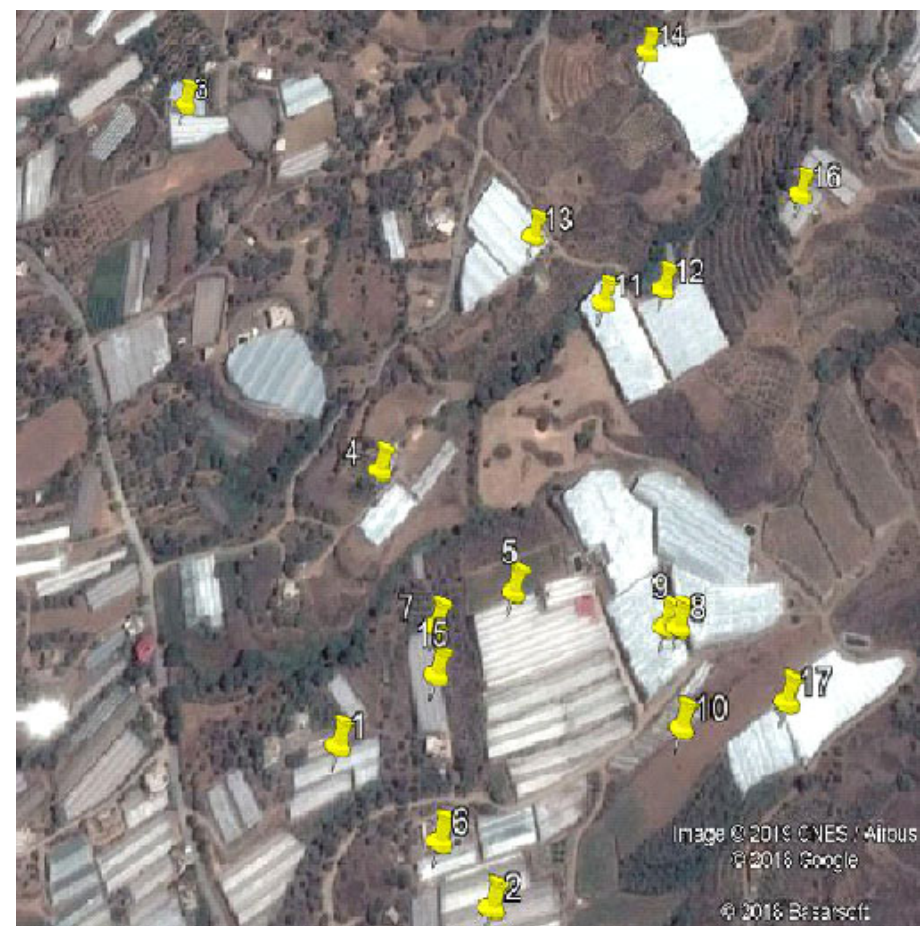

Çizelge 1. Gazipaşa ilçesinden örnek alınan yerlerin koordinatları

\begin{tabular}{|l|l|l|}
\hline Örnek No & X-GPS & Y-GPS \\
\hline 1 & 443443 & 4011287 \\
\hline 2 & 443560 & 4011193 \\
\hline 3 & 443250 & 4011772 \\
\hline 4 & 443447 & 4011463 \\
\hline 5 & 443681 & 4011290 \\
\hline 6 & 442862 & 4011188 \\
\hline 7 & 445848 & 4008210 \\
\hline 8 & 443678 & 4011378 \\
\hline 9 & 443667 & 4011332 \\
\hline 10 & 445814 & 4005514 \\
\hline 11 & 443608 & 4011596 \\
\hline 12 & 443654 & 4011568 \\
\hline 13 & 443549 & 4011621 \\
\hline 14 & 443634 & 4011754 \\
\hline 15 & 443507 & 4011327 \\
\hline 16 & 443760 & 4011627 \\
\hline 17 & 443752 & 4011301 \\
\hline
\end{tabular}

Şekil 1. Gazipaşa ilçesinden alınan örneklerin yerleri 


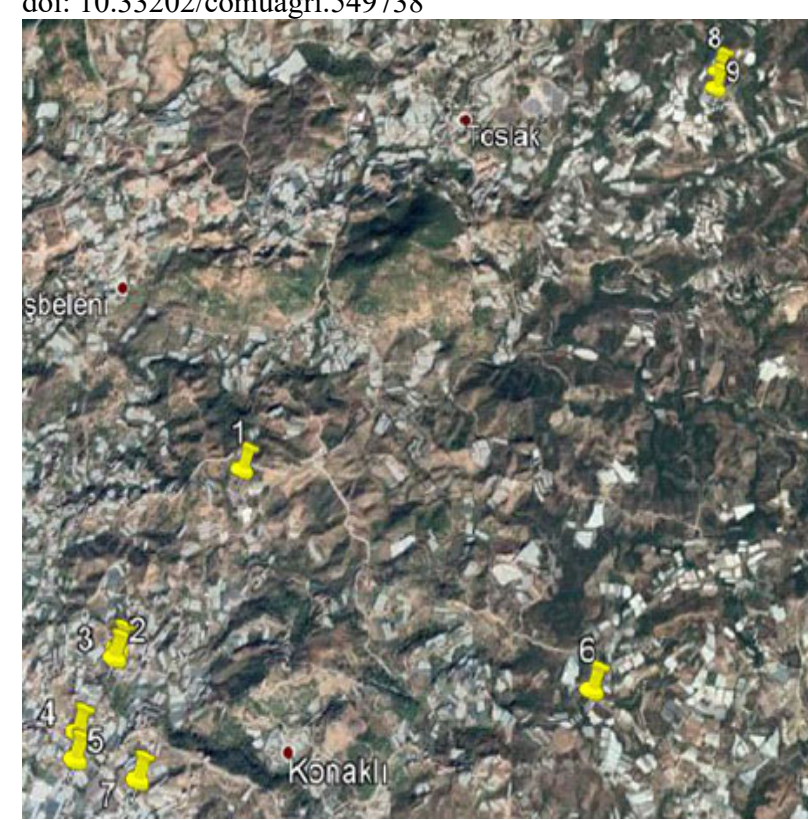

Çizelge 2. Alanya ilçesinden örnek alınan

yerlerin koordinatları

\begin{tabular}{|l|l|l|}
\hline Örnek No & X-GPS & Y-GPS \\
\hline 1 & 400755 & 4051782 \\
\hline 2 & 400119 & 4050709 \\
\hline 3 & 400109 & 4050707 \\
\hline 4 & 399957 & 4050302 \\
\hline 5 & 399965 & 4050156 \\
\hline 6 & 400633 & 4050071 \\
\hline 7 & 400360 & 4050039 \\
\hline 8 & 403753 & 4054375 \\
\hline 9 & 403735 & 4054302 \\
\hline
\end{tabular}

Şekil 2. Alanya ilçesinden alınan örneklerin yerleri

Toprak örnekleri Jackson (1967) tarafindan bildirilen esaslara göre 0-30 cm derinlikten alınmıştır. Alınan örneklerin bünyesi Bouyoucos hidrometre (Bouyoucos, 1955) metoduna göre, $\mathrm{pH}$ ve elektriksel iletkenliği (EC) 1/2.5 toprak su karışımında (Jackson, 1967), kireç $\left(\mathrm{CaCO}_{3}\right)$ içeriği Scheibler kalsimetresi kullanılarak (Evliya, 1964), organik madde (OM) miktarı modifiye WalkeyBlack (Black, 1965) metoduna göre belirlenmiştir. Topraklarda toplam N belirlemesi modifiye Kjeldahl yaş yakma (Black, 1957) yöntemine, alınabilir P belirlemesi 0.5 M sodyum bikarbonat $\left(\mathrm{NaHCO}_{3}, \mathrm{pH}: 8.5\right)$ ekstraksiyonu ile mavi renk yöntemine (Olsen ve Sommers, 1982), alınabilir K, Ca ve $\mathrm{Mg}$ belirlemeleri nötr $1 \mathrm{~N}$ amonyum asetat $\left(\mathrm{CH}_{3} \mathrm{COONH}_{4}, \mathrm{pH}: 7.0\right)$ çözeltisiyle ekstraksiyon yöntemine (Kacar, 1995) ve alınabilir $\mathrm{Fe}, \mathrm{Zn}, \mathrm{Mn}$ ve $\mathrm{Cu}$ belirlemeleri ise $0.005 \mathrm{M}$ dietilen triamin penta asetik asit DTPA $+0.1 \mathrm{M}$ trietanol amin (TEA)+0.01 $\mathrm{M}$ kalsiyum klorür $\left(\mathrm{CaCl}_{2}\right)$ karışım çözeltisi (pH:7.3) ile ekstraksiyon yöntemine göre (Lindsay ve Norwell, 1978) yapılmıştır.

Geraldson ve ark. (1973) tarafından tarif edildiği şekilde domates bitkisinin üstten itibaren 5. ya da 6. yaprakları örnek olarak alınmıştır. Alınan yaprak örnekleri Kacar ve İnal (2008)'ın bildirdiği gibi analize hazır hale getirilmiştir. Kurutulmuş ve ögütülmüş yaprak örneklerinde toplam N modifiye Kjeldahl yaş yakma metoduna göre ve toplam $\mathrm{P}, \mathrm{K}, \mathrm{Ca}, \mathrm{Mg}, \mathrm{Fe}, \mathrm{Zn}, \mathrm{Mn}$ ve $\mathrm{Cu}$ konsantrasyonları ise mikrodalga'da (Cem-Mars X5) yaş yakma metodu ile elde edilen süzükte ICP (Varian-720 ES) kullanılarak belirlenmiştir (Kacar ve İnal, 2008). Elde edilen toprak ve yaprak analiz sonuçları sınır değerleri ile karşılaştırılarak, sera topraklarının besin elementleri ile bitkilerin beslenme durumları değerlendirilmiştir.

\section{Bulgular ve Tartışma \\ Toprak Analizi Sonuçlart}

Gazipaşa ve Alanya ilçelerinden alınan toprak örneklerinin minimum ve maksimum değerleri Çizelge 3'de, sınır değerlerine göre sınıflandırılmaları ise Çizelge 4'de verilmiştir. Gazipaşa ilçesinde incelenen toprakların pH'ları 7,30-7,90 arasında değişmekte olup (Çizelge 3), örneklerin \%88,2'si hafif alkalin ve alkalin karaktere sahiptir (Çizelge 4). Alanya ilçesinden alınan toprakların pH'ları 7,50-8,0 arasında değişmekte olup (Çizelge 3), örneklerin tamamı hafif alkalin ve alkalin karaktere sahiptir. Maltaş ve Kaplan (2015), Antalya Merkez ilçede sonbahar dönemi domates yetiştiriciliği yapılan sera topraklarının \%87'sinin hafif alkalin ve alkalin karaktere sahip olduğunu belirlemişlerdir. Domates yetiştiriciliği açısından en uygun $\mathrm{pH}$ değerlerini Macit ve Ağme (1980)'ye göre 5,0-7,5 arasında ve Kovanc1 (1988)'ya göre ise 5,4-6,6 arasında olduğu bildirilmiştir. Buna göre incelenen toprak örneklerinin $\mathrm{pH}$ 'larının domates yetiştiriciliği açısından uygun olmadığı, özellikle $\mathrm{pH} \geq 7,5$ olduğunda mikro besin elementlerince beslenme sorunlarının ortaya çıkabileceği göz önünde bulundurulmalıdır. 
ÇOMÜ Zir. Fak. Derg. (COMU J. Agric. Fac.)

2019: 7 (1): 29-38

ISSN: $2147-8384$ / e-ISSN: 2564-6826

doi: 10.33202/comuagri.549738

Toprak örneklerinin kireç içerikleri düşük sınıfında yer alarak Antalya ilinden farklılık göstermektedir (Çizelge 4). Alpaslan ve ark. (2001), Gazipaşa ve Alanya ilçelerinde örtüaltı sebze yetiştiriciliği yapılan toprakların kireç içeriklerinin az kireçli (\%0-1) ve kireçli (\%1-5) sınıfında (Ülgen ve Yurtsever, 1995) yer aldığını bildirmişlerdir. Üreticilerin kimyasal ve organik gübre uygulamalarına bağlı olarak her iki ilçede de sera bazında toprak tuzluluk değerleri değişkenlik göstermekle birlikte tuzluluğa karşı toleranslı bir bitki olan domates'in Ayers ve Westcot (1989) tarafindan bildirilen optimum dayanım sınırı olan $2,5 \mathrm{dS} \mathrm{m}^{-1}$ tuzluluk değerini bir sera toprağı aşmıştır. Toprakta yüksek iyon konsantrasyonu (EC), fizyolojik kuraklık etkisiyle bitkinin su alımını dolayısıyla meyveye taşınmasını etkileyeceğinden yaş meyve ağırlığının azalmasına neden olacaktır (Suhardiyanto ve ark., 2009).

Çizelge 3. Gazipaşa ve Alanya ilçelerindeki domates seralarından alınan toprak örneklerinin bazı fiziksel ve kimyasal özelliklerine ilişkin minimum ve maksimum değerler

\begin{tabular}{|c|c|c|c|c|}
\hline \multirow[t]{2}{*}{ Toprak Özellikleri } & \multicolumn{2}{|c|}{ Gazipaşa } & \multicolumn{2}{|c|}{ Alanya } \\
\hline & Minimum & Maksimum & Minimum & Maksimum \\
\hline $\mathrm{pH}$ & 7,30 & 7,90 & 7,50 & 8,00 \\
\hline $\mathrm{CaCO}_{3}(\%)$ & 0,32 & 1,61 & 0,80 & 3,05 \\
\hline $\mathrm{EC}\left(\mathrm{dS} \mathrm{m}{ }^{-1}\right)$ & 0,41 & 2,73 & 0,18 & 0,80 \\
\hline OM $(\%)$ & 2,30 & 4,80 & 2,10 & 4,80 \\
\hline Toplam N(\%) & 0,11 & 0,24 & 0,13 & 0,24 \\
\hline Alınabilir $\mathrm{P}\left(\mathrm{mg} \mathrm{kg}^{-1}\right)$ & 52 & 238 & 81 & 184 \\
\hline Alınabilir $\mathrm{K}\left(\mathrm{mg} \mathrm{kg}^{-1}\right)$ & 129 & 954 & 111 & 670 \\
\hline Alınabilir $\mathrm{Ca}\left(\mathrm{mg} \mathrm{kg}^{-1}\right)$ & 2271 & 4266 & 1810 & 3398 \\
\hline Alınabilir $\mathrm{Mg}\left(\mathrm{mg} \mathrm{kg}^{-1}\right)$ & 272 & 1082 & 311 & 648 \\
\hline Alınabilir Fe $\left(\mathrm{mg} \mathrm{kg}^{-1}\right)$ & 2,65 & 10,30 & 5,38 & 26,5 \\
\hline Alınabilir $\mathrm{Zn}\left(\mathrm{mg} \mathrm{kg}^{-1}\right)$ & 2,39 & 19,37 & 1,07 & 9,95 \\
\hline Alınabilir $\mathrm{Mn}\left(\mathrm{mg} \mathrm{kg}^{-1}\right)$ & 2,68 & 18,42 & 2,30 & 55,85 \\
\hline Alınabilir $\mathrm{Cu}\left(\mathrm{mg} \mathrm{kg}^{-1}\right)$ & 0,82 & 25,73 & 1,85 & 18,39 \\
\hline
\end{tabular}

Çizelge 4. Gazipaşa ve Alanya ilçelerindeki domates seralarından alınan toprak örneklerinin sınır değerlerine göre siniflandırılması

\begin{tabular}{|c|c|c|c|c|c|c|}
\hline \multirow{2}{*}{$\begin{array}{l}\text { Toprak } \\
\text { Özellikleri }\end{array}$} & \multirow[t]{2}{*}{ Sınır değeri } & \multirow[t]{2}{*}{ Değerlendirme } & \multicolumn{2}{|c|}{ Gazipaşa } & \multicolumn{2}{|c|}{ Alanya } \\
\hline & & & $\begin{array}{l}\text { Örnek } \\
\text { Sayıs1 }\end{array}$ & $\%$ & $\begin{array}{l}\text { Örnek } \\
\text { Sayıs1 }\end{array}$ & $\%$ \\
\hline \multirow{4}{*}{$\begin{array}{c}\mathrm{pH} \\
(\text { Kellog, 1952) }\end{array}$} & $6,6-7,3$ & Nötr & 2 & 11,8 & - & - \\
\hline & $7,4-7,8$ & Hafif Alkalin & 12 & 70,6 & 5 & 55,6 \\
\hline & $7,9-8,4$ & Alkalin & 3 & 17,6 & 4 & 44,4 \\
\hline & $8,5-9,0$ & Kuvvetli Alkalin & - & - & - & - \\
\hline \multirow{5}{*}{$\begin{array}{c}\text { Kireç (\%) } \\
\text { (Evliya, 1964) }\end{array}$} & $0-2,5$ & Düşük & 17 & 100 & 8 & 88,9 \\
\hline & $2,6-5,0$ & Kireçli & - & - & 1 & 11,1 \\
\hline & $5,1-10,0$ & Yüksek & - & - & - & - \\
\hline & $10,1-20,0$ & Çok Yüksek & - & - & - & - \\
\hline & $20,0<$ & Aşır1 & - & - & - & - \\
\hline \multirow{6}{*}{$\begin{array}{c}\mathrm{EC}\left(\mathrm{dS} \mathrm{m}^{-1}\right) \\
\text { Dellavalle } \\
(1992)\end{array}$} & $0-0,400$ & Tuzsuz & - & - & 3 & 33,3 \\
\hline & $0,401-0,800$ & Hafif Tuzlu & 6 & 35,3 & 6 & 66,7 \\
\hline & $0,801-1,200$ & Orta Tuzlu & 4 & 23,5 & - & - \\
\hline & $1,201-1,600$ & Tuzlu & 4 & 23,5 & - & - \\
\hline & $1,601-3,200$ & Yüksek Tuzlu & 3 & 17,7 & - & - \\
\hline & $>3,201$ & Çok Yüksek Tuzlu & - & - & - & - \\
\hline \multirow{3}{*}{$\begin{array}{c}\text { Organik } \\
\text { Madde }(\%) \\
\text { Thun vd. }(1955)\end{array}$} & $0-2$ & Humusça Fakir & - & - & - & - \\
\hline & $2-5$ & Az Humuslu & 17 & 100 & 9 & 100 \\
\hline & $5-10$ & Humuslu & - & - & - & - \\
\hline \multirow{4}{*}{ Bünye } & \multirow{4}{*}{\multicolumn{2}{|c|}{$\begin{array}{l}\text { Tin } \\
\text { Kumlu Tin } \\
\text { Kumlu Killi Tin } \\
\text { Siltli Tin }\end{array}$}} & 4 & 23,6 & 1 & 11,1 \\
\hline & & & 6 & 35,3 & 7 & 77,8 \\
\hline & & & 1 & 5,8 & - & - \\
\hline & & & 6 & 35,3 & 1 & 11,1 \\
\hline Toplam & $0,070>$ & Çok Fakir & - & - & - & - \\
\hline
\end{tabular}




\begin{tabular}{|c|c|c|c|c|c|c|}
\hline \multirow{4}{*}{$\begin{array}{l}\text { N (\%) } \\
\text { Loué (1968) }\end{array}$} & $0-070-0,090$ & Fakir & - & - & - & - \\
\hline & $0,091-0,110$ & Orta & 1 & 5,8 & 1 & 11,1 \\
\hline & $0,111-0,130$ & 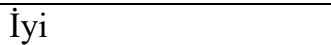 & 1 & 5,8 & 1 & 11,1 \\
\hline & $0,130<$ & Çok İyi & 15 & 88,4 & 7 & 77,8 \\
\hline \multirow{3}{*}{$\begin{array}{l}\text { Alınabilir P } \\
\left(\mathrm{mg} \mathrm{kg}^{-1}\right) \\
\text { Olsen ve } \\
\text { Sommers (1982) }\end{array}$} & $5>$ & Düşük & - & - & - & - \\
\hline & $5-10$ & Orta & - & - & - & - \\
\hline & $10<$ & Yeterli & 17 & 100 & 9 & 100 \\
\hline \multirow{3}{*}{$\begin{array}{l}\text { Alınabilir K } \\
\left(\mathrm{mg} \mathrm{kg}^{-1}\right)\end{array}$} & 100 & Çok Düşük & - & - & - & - \\
\hline & $100-200$ & Düşük & 2 & 11,8 & 4 & 44,4 \\
\hline & $200-250$ & Orta & 4 & 23,5 & 2 & 22,3 \\
\hline \multirow[t]{2}{*}{ Pizer (1967) } & $250-320$ & Yüksek & 1 & 5,8 & - & - \\
\hline & $>320$ & Çok Yüksek & 10 & 58,9 & 3 & 33,3 \\
\hline \multirow{3}{*}{$\begin{array}{l}\text { Alınabilir Ca } \\
\left(\mathrm{mg} \mathrm{kg}^{-1}\right)\end{array}$} & 715 & Çok Düşük & - & - & - & - \\
\hline & $715-1440$ & Düşük & - & - & - & - \\
\hline & $1440-2867$ & Orta & 6 & 35,3 & 4 & 44,4 \\
\hline \multirow[t]{2}{*}{ Loué (1968) } & $2867-6120$ & Yüksek & 11 & 64,7 & 5 & 55,6 \\
\hline & $>6120$ & Çok Yüksek & - & - & - & - \\
\hline \multirow{3}{*}{$\begin{array}{l}\text { Alınabilir Mg } \\
\left(\mathrm{mg} \mathrm{kg}^{-1}\right)\end{array}$} & $<55$ & Çok Düşük & - & - & - & - \\
\hline & $55-117$ & Düşük & - & - & - & - \\
\hline & $117-200$ & Orta & - & - & - & - \\
\hline \multirow[t]{2}{*}{ Loué (1968) } & $200-400$ & Yüksek & 5 & 29,4 & 2 & 22,2 \\
\hline & $>400$ & Çok Yüksek & 12 & 70,6 & 7 & 77,8 \\
\hline \multirow{3}{*}{$\begin{array}{l}\begin{array}{l}\text { Alınabilir Fe } \\
\left(\mathrm{mg} \mathrm{kg}^{-1}\right)\end{array} \\
\text { Lindsay ve } \\
\text { Norvel (1978) }\end{array}$} & $2,5>$ & Noksan & - & - & - & - \\
\hline & $2,5-4,5$ & Noksanlık gösterebilir & 8 & 47,0 & - & - \\
\hline & $4,5<$ & İyi & 9 & 53,0 & 9 & 100 \\
\hline \multirow{3}{*}{$\begin{array}{l}\text { Alınabilir Zn } \\
\left(\mathrm{mg} \mathrm{kg}^{-1}\right) \\
\text { Lindsay ve } \\
\text { Norvel (1978) }\end{array}$} & $0,5>$ & Noksan & - & - & - & - \\
\hline & $0,5-1,0$ & Noksanlık gösterebilir & - & - & - & - \\
\hline & $1,0<$ & İyi & 17 & 100 & 9 & 100 \\
\hline \multirow{2}{*}{$\begin{array}{l}\text { Alınabilir Mn } \\
\left(\mathrm{mg} \mathrm{kg}^{-1}\right) \\
\text { Lindsay ve } \\
\text { Norvel (1978) }\end{array}$} & $1,0>$ & Yetersiz & - & - & - & - \\
\hline & $1,0<$ & Yeterli & 17 & 100 & 9 & 100 \\
\hline \multirow{2}{*}{$\begin{array}{l}\begin{array}{l}\text { Alınabilir } \mathrm{Cu} \\
\left(\mathrm{mg} \mathrm{kg}^{-1}\right)\end{array} \\
\text { Lindsay ve } \\
\text { Norvel (1978) }\end{array}$} & $0,2<$ & Yetersiz & - & - & - & - \\
\hline & $0,2>$ & Yeterli & 17 & 100 & 9 & 100 \\
\hline
\end{tabular}

İncelenen sera toprak örneklerinin tamamının organik madde miktarı (\%2-5) yetersizdir. Seralarda bitki yetiştiriciliği dönemi boyunca, nem ve sıcaklık koşulları toprak organik maddesinin hızla parçalanmasına olanak tanımasından kayıplar artmaktadır. Seralara düzenli olarak organik materyal (çiftlik gübresi, kompost vs.) uygulansa bile bahsi geçen nedenlerden dolayı domates yetiştiriciliğ i için istenen \%5-8 toprak organik madde miktarı (Anderson, 2002) tespit edilememektedir. Ateş ve ark. (2016), sıcaklığın ve ayrışmanın fazla olduğu alanlarda iki yılda bir düzenli olarak ahır gübresi uygulanmasını önermektedirler.

Gazipaşa ilçesinde domates yetiştirilen sera topraklarının bünyeleri kumlu tın'dan siltli tın'a kadar değişkenlik gösterirken, Alanya ilçesindeki toprakların bünyesi tın ve kumlu tın'dır. Sera sebze yetiştiriciliğinde, iyi bir kök gelişimi için hafif bünyeli topraklar tercih edilmektedir. Bunun için üreticiler seralarına değişik mevkilerden kum ve toprak taşımaktadırlar (Sönmez ve Kaplan, 2007; Alagöz ve ark., 2006). Sera topraklarının kum içeriğinin arttırılması dolayısıyla toprak havalanmasının artması organik madde miktarının azalmasına neden olmaktadır.

Gazipaşa ve Alanya ilçelerinden alınan toprak örneklerinin toplam azot içerikleri iyi (Loué, 1968), alınabilir fosfor içerikleri ise yüksek (Olsen ve Sommers, 1982) sınıfında yer almıştır. Örneklerin organik madde miktarları düşük olmasına rağmen toprak azot konsantrasyonunun iyi olmasının yetiştiricilik periyodu boyunca uygulanan kimyasal gübrelerden kaynaklandığı 
düşünülmektedir. Gazipaşa ilçesindeki örneklerin \%88'inin, Alanya ilçesindekilerin ise \%56'sının alınabilir potasyum içerikleri yeterli ve yüksek sınıfındadır (Pizer, 1967). Arı ve ark., (2002), Antalya bölgesinde domates yetiştirilen sera topraklarının \%62,4'ünün yüksek ve çok yüksek düzeyde alınabilir $\mathrm{K}$ içerdiğini, alınabilir $\mathrm{P}$ açısından ise tamamının yüksek düzeyde olduğunu tespit etmişlerdir. İncelenen toprak örneklerinin alınabilir kalsiyum ve magnezyum konsantrasyonları yeterli ve yüksek düzeylerdedir. Sönmez ve Kaplan (2007), Antalya ili Demre ilçesinde domates yetiştirilen sera topraklarının alınabilir kalsiyum ve magnezyum içeriklerinin yeterli olduğunu bildirmişlerdir.

Gazipaşa ilçesinden alınan toprak örneklerinin tamamının alınabilir mangan, bakır ve çinko konsantrasyonları yeterli iken örneklerin \%47'sinin demir konsantrasyonu noksanlık gösterebilir sınıfındadır. Demir elementinin topraktaki yarayışılılığını alkalin $\mathrm{pH}$, kireç miktarı, toprağın fosfor, kalsiyum ve bikarbonat konsantrasyonu vb. faktörler etkilemektedir. Demir elementinin noksanlığ domates verim ve kalite kayıplarına yol açtığından, üreticiler demir uygulamalarına oldukça önem vermektedirler. Noksanlığın giderilmesi için kullanılan $\mathrm{Fe}$-şelatlı gübreler, üretim aşamasında kullanılan diğer tüm gübrelerden pahalıdır. Kimyasal gübre maliyetinin \%25'ini Fe-şelatlı gübreler oluşturmaktadır (Öktüren Asri ve Sönmez, 2016). Alanya ilçesinden alınan toprak örneklerinin alınabilir mikro element konsantrasyonları yeterlidir (Çizelge 4).

\section{Yaprak Analiz Sonuçları}

Gazipaşa ve Alanya ilçelerinden alınan yaprak örneklerinin analiz sonuçlarına ilişkin minimum ve maksimum değerler Çizelge 5'te verilmiştir. Gazipaşa ilçesinden alınan yaprak örneklerinde kuru madde de $\mathrm{N}$ konsantrasyonu \%4,47-6,21, P konsantrasyonu \%0,37-0,77, K konsantrasyonu \%1,51-2,44, Ca konsantrasyonu \%2,31-4,03, Mg konsantrasyonu \%0,26-0,59, Fe konsantrasyonu 53,1-113,2 mg/ kg, Zn konsantrasyonu 26,6-425,0 mg/kg, Mn konsantrasyonu 31,3187,0 ve $\mathrm{Cu}$ konsantrasyonu 9,0-303,0 mg/kg arasında değişmiştir. Elde edilen analiz sonuçlarının Campbell (2000) tarafından bildirilen yeterlilik sınır değerleriyle karşılaştırılması Çizelge 6'da verilmiştir. Gazipaşa ilçesindeki seralarda yetiştirilen domates bitkilerinin azot, fosfor ve kalsiyum konsantrasyonları yeterli ve yüksek sınıfında yer alırken potasyum konsantrasyonları düşük sınıfında yer almıştır (Çizelge 6). Maltaş ve Kaplan (2015), Antalya Merkez ilçede sonbahar döneminde yetiştirilen domates bitkilerinin $\mathrm{N}, \mathrm{P}, \mathrm{Ca}$ ve $\mathrm{Mg}$ konsantrasyonlarının genelde iyi düzeyde olduğunu, ancak K konsantrasyonunun tüm örneklerde yetersiz olduğunu bildirmişlerdir.

Domates yaprak örneklerinin $\mathrm{Zn}$ ve $\mathrm{Cu}$ konsantrasyonları yeterli ve yüksek; $\mathrm{Mn}$ konsantrasyonu ise yeterli düzeydedir. Sera topraklarının tamamında $\mathrm{Cu}$ ve $\mathrm{Mn}$ konsantrasyonlarının yeterli oluşu, bitki yapraklarında $\mathrm{Cu}$ ve $\mathrm{Mn}$ noksanlığı olmamasını doğrulamaktadır. Bitkilerin bir kısmında yüksek düzeyde $\mathrm{Cu}$ bulunmasının, yaprak gübresi ve ilaç uygulamalarından kaynaklandığı düşünülmektedir.

Alanya ilçesinden alınan yaprak örneklerinde kuru madde de $\mathrm{N}$ konsantrasyonu \% 4.28-5.56, $\mathrm{P}$ konsantrasyonu \%0,51-1,19, K konsantrasyonu \%2,39-3,30, Ca konsantrasyonu \%1,0-4,22, Mg konsantrasyonu \%0,20-0,57, Fe konsantrasyonu 60,4-116,4 mg/kg, Zn konsantrasyonu 4,5-101,0 mg/ $\mathrm{kg}$, Mn konsantrasyonu 11,0-332,0 ve Cu 5,7-56,6 mg kg-1 arasında değişmiştir. Campbell (2000) yeterlilik sınır değerlerine göre değerlendirilen yaprak örneklerinin $\mathrm{N}, \mathrm{P}, \mathrm{Ca}, \mathrm{Mn}$ ve $\mathrm{Cu}$ konsantrasyonları yeterli ve yüksek sınıfında yer almıştır (Çizelge 6). Çalışmada Pizer (1967)'a göre sınıflandırılan toprak örneklerinin birçoğunun alınabilir K konsantrasyonları yeterli iken (Çizelge 4), yaprak örneklerinin tamamının $\mathrm{K}$ konsantrasyonlarının düşük olduğu, ancak yaprak örneklerinde noksanlık belirtilerinin olmadığı tespit edilmiştir (Çizelge 6). Alpaslan ve ark. (2001), Akdeniz Bölgesi'nde domates yetiştiriciliği yapılan seralardan alınan yaprak örneklerinin \%93'ünün K konsantrasyonunun yetersiz olduğunu saptamışlardır. Orman ve Kaplan (2004), Kumluca ve Finike ilçelerindeki seralarda yetiştirilen domates bitkilerinin potasyum beslenme durumunun yetersiz olduğunu bildirmişlerdir.

Sera topraklarının tümünün $\mathrm{Zn}$ konsantrasyonları yeterli olduğu halde (Çizelge 4), yaprak örneklerinin \%44,5'inin Zn konsantrasyonu düşüktür (Çizelge 6). Toprak Zn konsantrasyonu noksan sınıfında yer alan sera topraklarının Ca ve Mg konsantrasyonları yüksektir. Nitekim çinko'nun Ca ve $\mathrm{Mg}$ karbonatlarca absorbe edilerek yarayışlılığının düşürüldüğü bilinmektedir (Kacar ve Katkat, 2006). Bununla birlikte örnek alma döneminde $\mathrm{Zn}$ noksanlık bulgularına rastlanmamıştır. Bu durumun domatesin çinkoya orta derecede hassas bitkiler sınıfinda yer almasından (Kacar ve Katkat, 2006) kaynaklanabileceği düşünülmektedir. 
Çizelge 5. Gazipaşa ve Alanya ilçelerindeki domates seralarından alınan yaprak örneklerine ilişsin minimum ve maksimum değerler

\begin{tabular}{lllll}
\hline Besin Elementi & \multicolumn{3}{c}{ Gazipaşa } & Alanya \\
\cline { 2 - 5 } & Minimum & Maksimum & Minimum & Maksimum \\
\hline $\mathrm{N}(\%)$ & 4,47 & 6,21 & 4,28 & 5,56 \\
$\mathrm{P}(\%)$ & 0,37 & 0,77 & 0,51 & 1,19 \\
$\mathrm{~K}(\%)$ & 1,51 & 2,44 & 2,39 & 3,30 \\
$\mathrm{Ca}(\%)$ & 2,31 & 4,03 & 1,0 & 4,22 \\
$\mathrm{Mg}(\%)$ & 0,26 & 0,59 & 0,20 & 0,57 \\
$\mathrm{Fe}\left(\mathrm{mg} \mathrm{kg}^{-1}\right)$ & 53,1 & 113,2 & 60,4 & 116,4 \\
$\left.\mathrm{Zn} \mathrm{(mg} \mathrm{kg}{ }^{-1}\right)$ & 26,6 & 425,0 & 4,5 & 101,0 \\
$\mathrm{Mn}\left(\mathrm{mg} \mathrm{kg}^{-1}\right)$ & 31,3 & 187,0 & 11,0 & 332,0 \\
$\mathrm{Cu}\left(\mathrm{mg} \mathrm{kg}^{-1}\right)$ & 9,0 & 303,0 & 5,7 & 56,6 \\
\hline
\end{tabular}

Çizelge 6. Gazipaşa ve Alanya ilçelerindeki domates seralarından alınan domates yaprak örneklerinin sınır değerlerine göre sınıflandırılması

\begin{tabular}{|c|c|c|c|c|c|c|}
\hline \multirow{2}{*}{$\begin{array}{l}\text { Bitki Besin } \\
\text { Elementi }\end{array}$} & \multirow[t]{2}{*}{ Sınır değeri } & \multirow[t]{2}{*}{ Değerlendirme } & \multicolumn{2}{|c|}{ Gazipaşa } & \multicolumn{2}{|c|}{ Alanya } \\
\hline & & & Örnek Sayısı & $\%$ & Örnek Sayısı & $\%$ \\
\hline \multirow{3}{*}{$\mathrm{N}(\%)$} & $3,5>$ & Düşük & - & - & - & - \\
\hline & $3,5-5,0$ & Yeterli & 11 & 64,7 & 5 & 55,5 \\
\hline & $5,0<$ & Yüksek & 6 & 35,3 & 4 & 44,5 \\
\hline \multirow{3}{*}{$\mathrm{P}(\%)$} & $0,30>$ & Düşük & - & - & - & - \\
\hline & $0,30-0,65$ & Yeterli & 12 & 70,6 & 1 & 11,1 \\
\hline & $0,65<$ & Yüksek & 5 & 29,4 & 8 & 88,9 \\
\hline \multirow{3}{*}{$\mathrm{K}(\%)$} & $3,5>$ & Düşük & 17 & 100 & 9 & 100 \\
\hline & $3,5-4,5$ & Yeterli & - & - & - & - \\
\hline & $4,5<$ & Yüksek & - & - & - & - \\
\hline \multirow{4}{*}{$\mathrm{Ca}(\%)$} & $1,0>$ & Düşük & - & - & - & - \\
\hline & $1,0-3,0$ & Yeterli & 5 & 29,4 & 2 & 22,2 \\
\hline & $3,0<$ & Yüksek & 12 & 70,6 & 7 & 77,8 \\
\hline & $0,35>$ & Düşük & 3 & 17,6 & 3 & 33,3 \\
\hline \multirow{3}{*}{$\operatorname{Mg}(\%)$} & $0,35-1,00$ & Yeterli & 14 & 82,4 & 6 & 66,7 \\
\hline & $1,00<$ & Yüksek & - & - & - & - \\
\hline & $50>$ & Düşük & - & - & - & - \\
\hline \multirow[t]{2}{*}{$\mathrm{Fe}\left(\mathrm{mg} \mathrm{kg}^{-1}\right)$} & $50-300$ & Yeterli & 17 & 100 & 9 & 100 \\
\hline & $300<$ & Yüksek & - & - & - & - \\
\hline \multirow{3}{*}{$\mathrm{Zn}\left(\mathrm{mg} \mathrm{kg}^{-1}\right)$} & $18>$ & Düşük & - & - & 4 & 44,5 \\
\hline & $18-80$ & Yeterli & 9 & 52,9 & 4 & 44,5 \\
\hline & $80<$ & Yüksek & 8 & 47,1 & 1 & 11,0 \\
\hline \multirow{3}{*}{$\operatorname{Mn}\left(\mathrm{mg} \mathrm{kg}^{-1}\right)$} & $25>$ & Düşük & - & - & 1 & 11,1 \\
\hline & $25-200$ & Yeterli & 17 & 100 & 6 & 66,7 \\
\hline & $200<$ & Yüksek & - & - & 2 & 22,2 \\
\hline \multirow{3}{*}{$\mathrm{Cu}\left(\mathrm{mg} \mathrm{kg}^{-1}\right)$} & $5,0>$ & Düşük & - & - & - & - \\
\hline & $5,0-35$ & Yeterli & 5 & 29,4 & 7 & 77,8 \\
\hline & $35<$ & Yüksek & 12 & 70,6 & 2 & 22,2 \\
\hline
\end{tabular}

Yapılan araştırmada domates bitkisi yaprak örneklerinin besin elementi konsantrasyonları ile toprak örneklerinin fiziksel ve kimyasal özellikleri arasındaki ilişkiler belirlenerek Çizelge 7'de verilmiştir. Toprak pH'sı ile yaprak $\mathrm{Cu}\left(\mathrm{r}=-0,410^{*}\right)$ ve $\mathrm{Ca}\left(\mathrm{r}=-0,396^{*}\right)$ konsantrasyonları arasında negatif ilişki bulunmuştur (Çizelge 7). Saatçı (1984), toprak reaksiyonunun $\geq 7,5$ üzerinde olması durumunda bitkinin $\mathrm{Cu}$ alımının azaldığını bildirmiştir. Toprak $\mathrm{CaCO}_{3}$ miktarı ile yaprak $\mathrm{Cu}(\mathrm{r}=-$ $\left.0,405^{*}\right)$ arasinda negatif, yaprak $\mathrm{K}\left(\mathrm{r}=0,543^{*}\right)$ ve $\mathrm{P}\left(\mathrm{r}=0,397^{*}\right)$ konsantrasyonları arasında pozitif ilişkiler tespit edilmiştir. Özbek (1975), kireçli topraklarda, $\mathrm{Cu}$ güç erir tuzlar halinde çökeldiğinden toprak çözeltisindeki $\mathrm{Cu}$ konsantrasyonu azalacağını, böylece bitkilerin $\mathrm{Cu}$ alımının zorlaşacağını bildirmektedir. Kaplan ve ark. (1995), Antalya Bölgesi domates seralarında yürüttükleri çalışmada, yaprak K konsantrasyonu ile toprağın kireç miktarı arasında pozitif ilişkiler tespit etmişlerdir. Yaprak 
örneklerinin $\mathrm{P} \quad\left(\mathrm{r}=0,599^{*}\right)$ ve $\mathrm{K}$ konsantrasyonları $\left(\mathrm{r}=0,605^{*}\right)$ ile toprak örneklerinin $\mathrm{Fe}$ konsantrasyonları arasında pozitif ilişkiler belirlenmiştir.

Çizelge 7. Yaprak örneklerinin besin elementi konsantrasyonları ile toprak örneklerinin fiziksel ve kimyasal özellikleri arasındaki önemli ilişkiler

\begin{tabular}{clcl}
\hline Bitki $(\mathrm{y})$ & Toprak $(\mathrm{x})$ & Korelasyon katsayısı $(\mathrm{r})$ & Regresyon eşitliğ \\
\hline \multirow{2}{*}{$\mathrm{P}$} & $\mathrm{CaCO}_{3}$ & $0,397^{*}$ & $\mathrm{y}(\mathrm{P})=0,5248949+0,1272479 \times(\mathrm{CaCO})$ \\
& $\mathrm{Fe}$ & $0,599^{*}$ & $\mathrm{y}(\mathrm{P})=0,4940679+0,0222157 \times(\mathrm{Fe})$ \\
$\mathrm{K}$ & $\mathrm{CaCO}_{3}$ & $0,543^{*}$ & $\mathrm{y}(\mathrm{K})=1,7658298+0,4723785 \times\left(\mathrm{CaCO}_{3}\right)$ \\
$\mathrm{Fa}$ & $\mathrm{pH}$ & $0,605^{*}$ & $\mathrm{y}(\mathrm{K})=1,8192163+0,0609015 \times(\mathrm{Fe})$ \\
$\mathrm{Mg}$ & $\mathrm{Cu}$ & $-0,396^{*}$ & $\mathrm{y}(\mathrm{Ca})=12,032048-1,1488896 \times(\mathrm{pH})$ \\
$\mathrm{Fe}$ & $\mathrm{P}$ & $-0,410^{*}$ & $\mathrm{y}(\mathrm{Mg})=0,4791944-0,0064649 \times(\mathrm{Cu})$ \\
& $\mathrm{Mn}$ & $0,486^{*}$ & $\mathrm{y}(\mathrm{Fe})=58,521758+0,189142 \times(\mathrm{P})$ \\
$\mathrm{Cu}$ & $\mathrm{pH}$ & $0,407^{*}$ & $\mathrm{y}(\mathrm{Fe})=76,982746+0,6236329 \times(\mathrm{Mn})$ \\
& $\mathrm{CaCO}_{3}$ & $-0,410^{*}$ & $\mathrm{y}(\mathrm{Cu})=1390,5592-171,82373 \times(\mathrm{pH})$ \\
& & $-0,405^{*}$ & $\mathrm{y}(\mathrm{Cu})=141,96984-63,744862 \times(\mathrm{CaCO})$ \\
\hline
\end{tabular}

\section{Sonuç ve Öneriler}

Antalya ili Gazipaşa ve Alanya ilçelerinde bulunan sera topraklarının verimlilik durumlarının ve domates bitkilerinin beslenme durumlarının incelendiği bu araştırmada elde edilen sonuçlar şu şekilde özetlenebilir. İncelenen sera topraklarının büyük çoğunluğu hafif alkalin ve alkalin reaksiyonlu olup az kireç içeriğine sahiptirler. Domates bitkisinin hafif asit ve nötr koşulları tercih ettiği ve yetiştiriciliğinin daha iyi yapılabildiği göz önüne alındığında üreticilerin kullandıkları besin çözeltilerinin pH'sını 6,5-7,0 arasında ayarlamaları, bitki besin maddeleri arasındaki antagonistik etkiden kaynaklanabilecek beslenme sorunlarının azalmasına yol açacaktır.

Domates seralarının tamamının organik madde içerikleri değerlendirildiğinde az humuslu ve humusça fakirdir. Organik maddenin toprakların genel fiziksel özelliklerini iyileştirici etkisinin yanı sıra dengeli bir bitki besin kaynağı olduğu göz önüne alındığında, topraklardaki miktarını arttırıcı önlemlerin alınması önerilebilir. Yetiştirme sezonu sonunda domates bitkisi yetiştirilen sera alanlarından tonlarca hasat sonrası atık oluşmaktadır. Söz konusu atıkların değerlendirilmesi konusunda toplum bilincinin zayıf olması, bu konuda belirlenmiş ve uygulamaya konmuş devlet politikalarının ve düzenlemelerin olmaması gibi nedenlerle atıklar ya yakılmakta ya da Belediyelerce gösterilen boş arazilere dökülmektedirler. Bu şekilde bitkilerin farklı organlarıyla topraktan kaldırdıkları bitki besin maddeleri heba edilmektedir. Söz konusu atıkların kompost yapılarak kullanılması ile hem toprakta organik madde miktarı artırılabilir hem de bitki besin elementlerinin geri dönüşümü sağlanabilir. Ülkemizin doğal gaz, fosfat kayası ve potasyum tuzu gibi hammadde kaynaklarına yeterince sahip olmadığı ve gübre sektörünün üretim girdileri açısından tamamen yurtdışına bağlı olduğu göz önüne alındığında bitki besin maddelerinin geri dönüşümünün önemi ortaya çıkmaktadır.

\section{Teşekkür} ederiz.

Çalışmaya 2013.Ç0393 nolu proje kapsamında maddi destek sağlayan Ulusal Bor Araştırma Enstitüsü’ne teşekkür

\section{Kaynaklar}

Akınoğlu, G., Korkmaz, A., 2016. Topraksız tarımda farklı substrat miktarı ve besin çözeltisi uygulamalarının domateste beslenme ve verim kriterlerine etkisi. Toprak Bilimi ve Bitki Besleme Dergisi. 4(2):49-56.

Aksoy, A., Kaymak, H.Ç., 2016. Outlook on Turkish Tomato Sector. Iğdır Üniversitesi Fen Bilimleri Enstitüsü Dergisi. 6(2):121-129.

Alagöz, Z., Öktüren, F., Yılmaz, E., 2006. Antalya Bölgesinde Karanfil Yetiştirilen Sera Topraklarının Bazı Verimlilik Özelliklerinin Belirlenmesi. Akdeniz Üniversitesi Ziraat Fakültesi Dergisi. 19(1):123-129.

Alpaslan, M., Güneş, A., İnal, İ., Aktaş, M., 2001. Akdeniz bölgesi seralarında yetiştirilen bitkilerin beslenme durumlarının incelenmesi I.sera topraklarının verimlilik durumları. Tarım Bilimleri Dergisi. 7(1):47-55.

Anderson, RG., 2002. Production of Greenhouse Tomatoes in Soil Beds. Hort Facts 8-02.UK Cooperative Extension Service. 
Arı, N., Ateş, T., Özkan, C.F., Arpacıoğlu, A.E., 2002. Antalya Bölgesi’nde Domates Yetiştiriciliği Yapılan Seraların Toprak Verimlilik Durumlarının İncelenmesi. 4. Sebze Tarımı Sempozyumu. s. 171-179. 17-20 Eylül, Bursa.

Arı, N., Özkan, C.F., Demirtaş, E.I., Güven, D., Öktüren Asri, F., Şimşek, M., 2019. Antalya Demre İlçesi Domates Seralarının Toprak Özellikleri ve Bitki Besleme Potansiyelleri. 8.Ulusal Bitki Besleme ve Gübre Kongresi Bildiri Özetleri Kitab1, s.9. 12-15 Mart, Antalya.

Ateş, F., Kuştutan, F., Dardeniz, A., Yüksel, S., 2016. Alaşehir'de (Manisa) Mevlana Üzüm Çeşidi Yetiştirilen Bağ Topraklarının Bazı Fiziksel ve Kimyasal Özelliklerinin Belirlenmesi. ÇOMÜ Ziraat Fakültesi Dergisi. 4(2):37-43.

Ayers, R.S., Westcot, D.W., 1989. Water Quality for Agriculture. Irrigation and Drainage Paper, 29 Rev.1., New York.

Black, C.A., 1957. Soil-Plant Relationships. John Wiley and Sons, Inc., Newyork.

Black, C.A., 1965. Methods of soil analysis, part 2, chemical and microbiological properties, American Society of Agronomy Inc., Publisher Madison, Wilconsin, USA., 1372-1376.

Bouyoucos, G.J., 1955. A recalibration of the hydrometer method for making mechanical analysis of the soils. Agronomy Journal. 4(9):434.

Campbell, C.R., 2000. Reference Sufficiency Ranges Vegetables Crops. Tomato, Greenhouse. http://www. ncagr.com/agronomi/saaesd/gtom.htm. Erişim Tarihi: 03.03.2019

Dellavalle, N.B., 1992. Determination of Specific Conductance in Supertanat 1:2 Soil:Water Solution. In Handbook on Reference Methods for Soil Analysis. Soil and Plant Analysis Council, Inc. Athens, GA.

Evliya, H., 1964. Kültür bitkilerinin beslenmesi. Ankara Üniversitesi Ziraat Fakültesi Yayınları, Sayı:10.

FAO, 2017. Food and Agriculture Organization of the United Nations. http://faostat3.fao.org/download/Q/QC/E.

Geraldson, C.M., Klacan, G.R., Lorenz, O.A., 1973. Plant Analysis as an Aid in Fertilizing Vegetable Crops, Soil Testing and Plant Analysis. Soil Science of America Inc., Madison, Wisconsin, USA.

Jackson, M.L., 1967. Soil Chemical Analysis. Prentice Hall of India Private Limited, New Delhi.

Kacar, B., 1995. Toprak analizleri. Bitki ve toprağın kimyasal analizleri: III. Ankara Üniversitesi Ziraat Fakültesi Eğitim Araştırma ve Geliştirme Vakfı Yayınları, No:3, Ankara.

Kacar, B., Katkat, V., 2006. Bitki Besleme. Nobel Yayın No:849.

Kacar, B., İnal, A., 2008. Bitki Analizleri. Nobel Yayın No:1241.

Kandemir, D., Kurtar, E.S., Demirsoy, M., 2016. Türkiye Örtüaltı Domates Yetiştiriciliğindeki Gelişmeler. www.turktob.org.tr Erişim Tarihi:01.03.2019.

Kaplan, M., Köseoğlu, T., Aksoy, T., Pilanalı, N., Sarı, M., 1995. Batı Akdeniz Bölgesinde Serada Yetiştirilen Domates Bitkisinin Beslenme Durumunun Toprak ve Yaprak Analizleri ile Belirlenmesi. TÜBİTAK Projesi. Proje No: TOAG-987/DPT-3, Antalya.

Kellog, C.E., 1952. Our Garden Soils. The Macmillan Company, New York.

Kovancı, İ., 1988. Bitki besleme ve toprak verimliliği notları. Ege Üniversitesi Ziraat Fakültesi Teksir No:107-1. 286 s. İzmir.

Lindsay, W.L., Norwell, W.A., 1978. Development of a DTPA Soil Test for Zinc, Iron, Manganese and Copper. Soil Science Society America Journal. 42(3):421-428.

Loué, A., 1968. Diagnostic Petiolaire de Prospection. Etudes Sur la Nutrition et al Fertilisation Potassiques de la Vigne. Societe Commerciale des Potasses d'Alsace Services Agroomiques. p:31-41.

Macit, F., Ağme, Y., 1980. Sebzeler ve Gübrelenmeleri. Bilgehan Matbaası, Bornova.

Maltaş, A.Ş., Kaplan, M., 2015. Antalya (Merkez İlçe)'da yetiştirilen örtüaltı güzlük domates bitkilerinin (Solanum lycopersicum L.) beslenme durumlarının belirlenmesi. Akdeniz Üniversitesi Ziraat Fakültesi Dergisi. 28(1):33-38.

Olsen, S.R., Sommers, E.L., 1982. Phosphorus Soluble in Sodium Bicarbonate, Methods of Soil Analysis, Part 2, Chemical and Microbiological Properties. Edit: A.L. Page, P.H. Miller, D.R. Keeney, 404-430.

Orman, Ş., Kaplan, M., 2004. Kumluca ve Finike İlçelerinde Serada Yetiştirilen Domates Bitkisinin Beslenme Durumunun Belirlenmesi. Akdeniz Üniversitesi Ziraat Fakültesi Dergisi. 17(1):19-29.

Öktüren Asri, F., Sönmez, S., 2016. Effects of Potassium and Iron Applications on Nutrient Concentrations of Tomato Plants Grown in Soilless Culture. Acta Horticulturae. 329-334.

Özbek, N.,1975. Toprak Verimliliği ve Gübreler, I. Toprak Verimliliği. Ankara Üniversitesi Ziraat Fakültesi Yayınları 525, Ders Kitabi 170.

Özkan, C.F., 2008. Antalya ve Çevresi Örtüaltı Domates Yetiştiriciliğinde Toprak Verimliliği, Bitki Besleme, Bazı Kalite ve Stres Parametreleri Arasındaki İlişkiler. Ege Üniversitesi Fen Bilimleri Enstitüsü, Toprak Ana Bilim Dalı, Doktora Tezi. $70 \mathrm{~s}$.

Pizer, N.H., 1967. Some Advisory Aspect. Soil Potassium and Magnesium, Technical Bullettin No.14:184.

Saatçı, F., 1984. Toprak İlmi. Ege Üniversitesi Ziraat Fakültesi Teksir No:85-1. İzmir

Sönmez, İ., Kaplan, M., 2007. Antalya-Demre İlçesinde Domates Yetiştirilen Sera Topraklarının Bazı Verimlilik Özelliklerinin Değerlendirilmesi. Akdeniz Üniversitesi Ziraat Fakültesi Dergisi. 20(1):29-35. 
ÇOMÜ Zir. Fak. Derg. (COMU J. Agric. Fac.)

2019: 7 (1): 29-38

ISSN: 2147-8384 / e-ISSN: 2564-6826

doi: 10.33202/comuagri.549738

Suhardiyanto, H., Arif, C., Setiawan, B.I., 2009. Optimization of EC Values of Nutrient Solution for Tomato Fruits Quality in Hydroponics System Using Artificial Neutral Network and Genetic Algorithms. Journal of Engineering and Technological Sciences. 41A(1):38-49.

Tatar, M., Pirinç, V., 2017. Potential of Industrial Tomato Production of Southeast Anatolian Region in Turkey. Iğdır Üniversitesi Fen Bilimleri Enstitüsü Dergisi. 7(2):11-20.

Thun, R., Hermann, R., Knickmann, E., 1955. Die Untersuchung Von Boden. Neuman Verlag, Radelbeul und Berlin, s:48.

Ülgen, N., Yurtsever, N., 1995. Türkiye Gübre ve Gübreleme Rehberi (4.Baskı). T.C. Başbakanlık Köy Hizmetleri Genel Müdürlüğü Toprak ve Gübre Araştırma Enstitüsü Müdürlüğü Yayınları, Genel Yayın No:209, Teknik Yayınlar No:T.66, s.230, Ankara. 